\title{
O ENSINO E A APRENDIZAGEM DA ESCRITA NA LÍNGUA MATERNA: DA TRANSDISCIPLINARIDADE AO COLONIALISMO IMPLÍCITO NOS GÊNEROS EXAMES DE LARGA ESCALA E AVALIAÇÕES DO DESEMPENHO DA APRENDIZAGEM DOS ALUNOS NAS SALAS DE AULA
}

\author{
THE TEACHING AND LEARNING OF WRITING IN THE MOTHER TONGUE: FROM \\ TRANSDISCIPLINARITY TO IMPLICIT COLONIALISM IN THE GENRES LARGE- \\ SCALE EDUCATION ASSESSMENTS AND EVALUATIONS OF STUDENTS LEARNING \\ PERFORMANCE IN CLASSROOMS
}

\author{
Roberto Baron*
}

\section{RESUMO}

A reflexão desenvolvida ao longo do artigo procura desvendar relações de poder que, discursivamente, estão presentes e causam efeitos de dominação, no confronto entre a avaliação escolar aplicada por um professor de disciplina do currículo escolar, desde a educação básica ao ensino médio, e os exames de larga escala que geram os dados e índices do SAEB - Sistema de Avaliação da Educação Básica, e o Programa Internacional de Avaliação de Estudantes - PISA, por exemplo. Entre os efeitos discursivos estão propostas de condicionamento autoritário, de padronização cultural e do conhecimento impostas a estudantes da escrita da língua materna que estas avaliações exercem entre si e sobre a aprendizagem. Busca-se apoio teórico e filosófico na dialogia e teoria de gênero, no conceito de transdisciplinaridade desenvolvido na Linguística Aplicada, LA, na análise crítica do discurso, na pedagogia histórico-crítica, interativa e da libertação. Relata-se sobre um histórico das ideias pedagógicas e um contexto das instituições nacionais e internacionais que aplicam as avaliações e os exames de larga escala. Desenvolve-se uma análise ideológica sobre como os exames de larga escala interferem nas provas aplicadas pelo professor nas escolas. Mostra-se uma análise comparativa entre as avaliações escolares e as avaliações de larga escala como resposta às inquietações que surgiram ao longo da reflexão, com sugestão para uma educação humanizadora, de superação e transformação social. Palavras-chave: linguística aplicada; avaliação escolar; exames de larga escala; educação humanizadora.

\section{ABSTRACT}

The reflection developed throughout the article seeks to unravel the power relations that, discursively, are present and cause dominance effects, in the confrontation between the school evaluation applied by discipline teachers of the school curriculum, from basic education to high school, and the large-scale exams generated by the data and indices of the SAEB - Basic Education Assessment System, and the International Student Assessment Program - PISA, for example. Among the discursive effects are the proposals of authoritarian conditioning, cultural standardization and knowledge imposed on students who are in the process of learning to write in their mother tongue. We seek theoretical and philosophical support in Bakhtin's theories of gender and dialogue, in the concept of transdisciplinarity developed in Applied Linguistics, LA, in critical discourse analysis, in historicalcritical, interactive, critical and liberation pedagogy. It reports on a history of pedagogical ideas and a context of national and international institutions applying large-scale evaluations and examinations. An ideological analysis is developed of how largescale examinations interfere with tests administered by teachers in schools. A comparative analysis between the evaluations in the classrooms and large-scale evaluations is shown in response to the concerns that arose during the reflection, with a suggestion of a humanizing education, of improvement and social transformation.

Keywords: Applied Linguistics; school evaluation; large-scale examinations; humanizing education

\section{INTRODUÇÃO}

Os gêneros discursivos e textuais, avaliações escolares para medir o aprendizado da escrita da língua materna no cotidiano das escolas, as avaliações escolares, e os exames de larga escala, provas aplicadas por instituições externas à escola, como a do ENEM e do PISA, apresentam-se carregados de posições e condições discursiva e ideologicamente produzidas pelos poderes políticos e sociais dominantes nas diferentes esferas das atividades humanas, destinadas a produzir efeitos de dominação ou libertação em professores, professoras e estudantes que são submetidos às avaliações escolares e aos exames de larga escala. Segundo Bonini (2014, p. 53), os gêneros são

\footnotetext{
* Doutorando no Programa de Pós-graduação em Linguística da Universidade Federal de Santa Catarina (UFSC), Florianópolis, SC, Brasil. r.baron@posgrad.ufsc.br e rorobato@gmail.com.

Orcid: https://orcid.org/0000-0002-2784-1518
} 
"unidades materializáveis na forma de texto e são reconhecidas e praticadas na comunidade discursiva de origem como uma unidade textual" e apresentam um "texto que ocorre como enunciado pleno ou recorte" (BONINI, 2014, p.54).

O debate sobre os gêneros discursivos e textuais foi ampliado na BNCC homologada em 14 de dezembro de

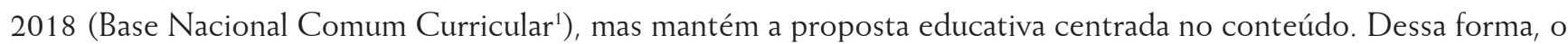
fraco desempenho de estudantes nos exames de larga escala, ainda poderia ser consequência da definição incompleta de gênero dos PCNs.

Esta deficiência conduz a uma metodologia de ensino que não leva em consideração as habilidades que o aluno deva desenvolver no decorrer da apropriação dos gêneros e, por sua vez, leva a um critério quase aleatório de seleção dos gêneros a serem ensinados. (BONINI, 2012, P.21),

A escola, que até o início da pandemia por covid-19, foi o local presencial em que as avaliações escolares e os exames de larga escala aconteciam presencialmente, é parte de um contexto maior, que exige dela, a formação e a preparação de pessoas para atuarem no mercado econômico, capitalista, por quem as escolas são "financiadas".

Neste sentido, com a tendência política e econômica vigente no Brasil, questiona-se se as avaliações escolares serviriam para medir se o indivíduo tem os conhecimentos linguísticos necessários e suficientes para atender, segundo Dardot e Laval (2009-2010, p.135) "a dimensão antropológica do homem-empresa"? Então, seriam os conhecimentos exigidos nos exames de larga escala os necessários e suficientes para que estudantes possam atuar/formar "homemempresas, governos empresariais e a fábrica do sujeito neoliberal" segundo preconizam Dardot e Laval (2009-2010, p.271-376)?

E, como e quais, como contrapartida ao neoliberalismo, seriam os conteúdos, as formas de ensino e aprendizagem necessárias para estimular "o comum" de acordo com as nove proposições do comum e a sua Praxis instituinte (DARDOT e LAVAL, 2014, p. 479 e 429)?

As incoerências entre, os processos de avaliação escolar e os exames de larga escala, entre os conhecimentos escolares e os saberes exigidos na vida real, que dizem medir a aprendizagem da escrita da língua materna também podem ser atribuídas à linguagem autoritária ou às intenções colonizadoras implícitas nos processos de avaliação escolar e nos exames de larga escala. Freire e Macedo (2011, p. 91) desafiam:

por que a maioria do povo está, atualmente, reduzida ao silêncio? Por que tem que abafar o próprio discurso? Quando são chamados a ler, por que leem apenas o discurso dominante? Os programas de alfabetização em geral oferecem ao povo o acesso a um discurso predeterminado e preestabelecido, enquanto silenciam sua própria voz, a qual deve ser amplificada na reinvenção da nova sociedade com a qual eu sonho.

O autoritarismo pode ser entendido no resultado contraditório das avaliações escolares e de exames de larga escala, quando comparados entre si: desempenho satisfatório nas avaliações escolares e insuficiente nos exames de larga escala. Poderia ser a consequência da privação de estudantes de processos de ensino e aprendizagem transdisciplinares que ampliariam e ligariam os conhecimentos linguísticos com os filosóficos, étnicos, sociológicos, geográficos, políticos, sexuais, econômicos e de saúde, por exemplo, que na realidade, coexistem e se auto influenciam.

No caso da pesquisa sócio-histórica, a maneira do fazer transdisciplinar em LA não tem dispensado um diálogo intenso com conceitos da filosofia, da sociologia e da política, da antropologia, das análises de discurso - em especial, teoria da comunicação bakhtiniana -, mas como vimos, ressignificados como facetas de interpretação do objeto de estudo e não como níveis estanques de análises. (ROJO, 2016, P. 273/274)

Enquanto as avaliações escolares também participam da formação das notas para o boletim de estudantes, os resultados dos exames de larga escala geram os índices que subsidiam as políticas educacionais na destinação dos investimentos em educação. E representam o diagnóstico para saber se estudantes aprenderam ou não. Segundo Vigotski (2017, p. 115), "a aprendizagem é um momento intrinsicamente necessário e universal para que se desenvolvam na criança essas características humanas não-naturais, mas formadas historicamente."

A avaliação escolar, conjugada aos exames de larga escala, representa uma das ferramentas contemporâneas que explora a "fraqueza humana de se submeter inquestionavelmente a poderosas instâncias (agencies) coletivas e

1. BNCC: acesso em 16 de outubro de 2020 no link http://basenacionalcomum.mec.gov.br/images/BNCC_EI_EF_110518_versaofinal_site. $\mathrm{pdf}$ 
externas.". O próprio Adorno (1951), completa, referindo-se a Freud, "ele busca descobrir quais forças psicológicas resultam na transformação de indivíduos em massa."

O efeito de massificação e conformismo não são apenas provocados pelos resultados das avaliações e exames em quem não consegue desempenho satisfatório, mas também em quem se dá bem e muito bem em ambas. Avaliações e exames estão a serviço da manutenção do sistema de padronização cultural, de manutenção das desigualdades sociais e da desumanização das pessoas na convivência nas esferas de atividades humanas. Neste confronto, predomina a ideologia, de que a culpa pelas notas baixas é de estudantes que não estudam e de professores e professoras que não sabem ensinar.

Os professores e professoras na defesa de seus métodos de trabalho e de ensino, seguem pesquisadores que recomendam fundamentos para guiar os processos de avaliação escolar como: a) Hoffmann (2013, p.13) "de que avaliar não se reduz a corrigir e a atribuir notas ou conceitos."; b) avaliar é constatar de que "nas condições de verdadeira aprendizagem os educandos vão se transformando em reais sujeitos da construção e da reconstrução do saber ensinado" (FREIRE, 1999, p. 29); c) avaliar também pode significar em contribuir inconscientemente com, segundo Lins (2003, p. 112) citando Marx (1982), "a obliteração intelectual dos adolescentes, artificialmente produzida com a transformação deles em simples máquinas de fabricar mais-valia,"; d) avaliar poderá ser entender o desenvolvimento da catarse, ou segundo Duarte $(2016$, p.18) ensinando para que o estudante desenvolva "saltos qualitativos decisivos em termos de desenvolvimento da visão de mundo dos indivíduos."; Ou ainda e) avaliar é desenvolver o potencial do sujeito concreto, não do sujeito empírico, não do sujeito unilateral, mas na formação do sujeito integral ou ainda promover "a formação humana omnilateral ", que, segundo Souza (2012, p. 103)

trata-se da apropriação pessoal de uma totalidade de forças produtivas que desenvolverá no indivíduo, além do espírito coletivo pelo qual estará disponível para a diversidade de atividades, a omnilateralidade por meio da unidade indissolúvel entre trabalho manual e intelectual, teórico e prático, em contraposição ao imperativo da fábrica e do ensino classista.

No entanto, todos os estudiosos citados, de alguma forma defendem a avaliação escolar e de larga escala como gêneros válidos para medir a aprendizagem, e, apesar das diferentes formas que apresentam, nenhum deles contesta veemente a necessidade de suprimir as avaliações escolares e os exames de larga escala como processos que medem a aprendizagem. Souza (2012), Lins (2003) citando Marx (1982) e Freire (1999), acima já referenciados, também incluem as transformações de atuação, individual e coletiva, dos sujeitos e indivíduos na tentativa de romper com a condição de classe a que estão submetidos. Caberia a professores e professoras, desenvolver os processos de ensino e aprendizagem na perspectiva de humanização da sociedade, de transformação social necessária para anular os efeitos de padronização, massificação e que evitem a alienação de atitudes e a reificação da forma de pensar de seus estudantes. Então surge uma questão difícil de analisar: como os exames de larga escala interferem nas ações e práticas pedagógicas dos professores de língua portuguesa?

Os exames de larga escala se valem de uma abordagem mais abrangente, no sentido de encobrir as reais intenções em relação à formação dos alunos, como a massificação e padronização cultural. E, professores e professoras, muitas vezes são pressionados até por alunos, a ensinar para que consigam ótimos desempenhos nestes exames, abandonando ou relegando a segundo plano a formação para a consciência linguística voltada para a autonomia e libertação da pessoa humana. Vivenciei este processo em quase todas as turmas e escolas para quem lecionei. Era pressionado, por estudantes e seus pais, a preparar estudantes do ensino médio para a prova do ENEM (Exame Nacional do Ensino Médio). Esse efeito nos transforma em instrumentos dos processos de massificação e padronização cultural.

As avaliações escolares deveriam também medir o conhecimento sobre o "mundo local" de estudantes, de professores e professoras e da própria escola, e porque não dizer, avaliar conhecimentos sobre as necessidades políticas, culturais, sociais, linguísticas e profissionais da comunidade em que a escola está situada, social e geograficamente. Os conhecimentos e pesquisas que ali são desenvolvidas, ensinadas e aprendidas, deveriam ser valoradas como diferenças para outros locais, e colaborar nas transformações sociais, políticas, econômicas e culturais necessárias na vida de estudantes e da própria comunidade. Segundo D’Souza (2010, p.111-112)

\footnotetext{
..., é preciso que a qualidade do conhecimento produzido pela pesquisa avaliada em função de seu poder transformador - ou seja, da sua capacidade de transformar as relações injustas e desiguais existentes no mundo tal como ele é hoje, bem como de transformar radicalmente as estruturas geradoras de opressão, da desigualdade e da injustiça.
} 
Esta reflexão, embora incompleta, aborda efeitos gerados pelas avaliações escolares aplicadas nas escolas na sua relação com os exames de larga escala, e das teorias e estudos acima expostos, aprofunda-se organizada em temas como: 1) Relações de poder nas propostas pedagógicas de avaliação escolar e exames de larga escala; 2) Quem manda: a avaliação escolar ou os exames de larga escala?; 3) Humanizar as atividades humanas?; 4) Humanizar: transformar as práticas sociais de avaliação escolar e dos exames de larga escala; 5) Capitalismo humanizado, é possível?; 6) Considerações finais; e 7) Referências.

\section{RELAÇÕES DE PODER NAS PROPOSTAS PEDAGÓGICAS DE AVALIAÇÃO ESCOLAR E EXAMES DE LARGA ESCALA}

Os métodos e os objetivos a medir através das avaliações escolares e exames de larga escala são influenciados pelas ideias pedagógicas que por sua vez estão a serviço do grupo político e econômico que detém ou chegou ao poder. A periodização das ideias pedagógicas no Brasil, desenvolvida por Saviani, (2013, p. 14), relata que, de 1549 até 1947, predomina a pedagogia tradicional, o positivismo. De lá para cá existem modismos ou correntes pedagógicas que abrangem a pedagogia nova, pedagogia tecnicista, emergência da pedagogia com concepções crítico-reprodutivistas, histórico-críticas, neoconstrutivistas, neotecnicistas e neoescolanovistas. A partir desta constatação histórica é possível inferir de que a criação das escolas e as respectivas práticas pedagógicas adotadas é inerente às correntes econômicas, políticas, filosóficas, culturais, geográficas e sociais predominantes no período histórico em questão e nas políticas de estado, eleitas, ou supostamente eleitas democraticamente, ou determinadas autoritariamente.

No período de mudanças e incertezas pedagógicas, sinalizado pelo quase completo desconhecimento sobre PPP (Plano Político Pedagógico) por parte de pais, estudantes, professores e professoras, a pedagogia tradicional filiada ao positivismo predominou e se manteve presente nas práticas pedagógicas, o que nos leva a deduzir, por empirismo de que o sistema de avaliação escolar também manteve a predominância da cobrança pela repetição de conteúdo ou do conhecimento através de uma prova na qual o aluno era, e ainda é, classificado de acordo com a quantidade de questões com erros e ou acertos. Para Luckesi $(2015$, p.13) "A avaliação da aprendizagem será abordada como um recurso subsidiário para a obtenção de resultados satisfatórios em ações pedagógicas planificadas no âmbito escolar." Neste caso é possível pensar que as ações pedagógicas e planificadas no âmbito escolar representam uma força para impedir de que "os homens se tornariam conscientes de sua posição social, e portanto, de suas tarefas, no terreno da ideologia". (GALASTRI, 2015, p. 65 ao citar MARX, 1983, p. 25)

As avaliações escolares também deveriam contribuir para a formação de um sujeito com visão de mundo para participar da humanização das atividades humanas nas suas diferentes esferas, buscando por transformações sociais necessárias de âmbito local, regional, nacional e global. Assim as instituições escolares se fortaleceriam assumindo a responsabilidade de formar as pessoas e para tanto, seguindo ao relato de Moita Lopes (2016, p.24): "Freire e Leffa argumentam que se fazem necessários saberes não lineares e não fragmentados, rizomaticamente interligados de modo transdisciplinar, dando conta do que é ambíguo, instável e imprevisível, quer dizer, da complexidade."

No entanto a fragmentação e a simplificação, o binário, foi predominante na educação brasileira com a justificativa de adequar os processos de ensino às condições de aprendizagem das crianças, considerando que elas não tinham a capacidade de assimilar pensamentos e conhecimentos complexos. Negligencia-se dessa forma, a condição de que a escrita é um complexo instrumento cultural.

Dessa maneira, a necessidade de escrever precisa ser engendrada em situações volitivas no processo de aprendizagem, requerendo um alto grau de consciência desses processos de apropriação da escrita como um complexo instrumento cultural. Isso postula um planejamento pedagógico da escrita como prática de uso social. (DANGIÓ \& MARTINS, 2018, p. 45)

A tendência em que domina a disputa do poder político e econômico é prioridade ante as necessidades de aprendizagem, como por exemplo, da escrita como uso social. Quando os grupos sociais de elite decidiram utilizar o estado para forçar a "família" a se dedicar ao trabalho nas empresas, incluindo objetivos como a transformação cultural referente ao controle da natalidade, e com isso a necessidade de incluir a mulher, crianças e pessoas de idade na força de trabalho capitalista e, ao mesmo tempo "produzir" um sujeito adequado às novas condutas "padrão" observando os novos códigos de moralidade, éticos, culturais, para manter a ordem econômica e social, transformando o ser humano em trabalho, impedindo que ele fosse linguagem, estes grupos incumbem a escola com o papel de "educadora" 
da sociedade, sem contudo permitir um planejamento pedagógico que busque a essência de formar pessoas com autonomia consciente para a produção escrita.

Diferentemente da linguagem oral, a escrita requer o emprego dos significados formais das palavras. Deve ser explícita e com máxima diferenciação sintática, isto é, a linguagem escrita é exigente, tanto em sua estrutura fonêmica quanto semântica. ... Outro ponto de diferenciação entre a linguagem oral e a linguagem escrita reside na motivação - resultado de uma necessidade. (DANGIÓ \& MARTINS, 2018 , p. 45)

Resumindo, o efeito de ausência de um alto grau de consciência, da complexidade e da motivação nos processos de ensino e aprendizagem da escrita da língua materna, não se justifica como sendo falta de formação dos professores e professoras de alfabetização, mas é possível entender como sendo um dos efeitos históricos para garantir a ausência de consciência política, social e de cidadania na população. Pois ao não entender o que a obrigam a escrever, a criança acaba não querendo aprender, e com isso terá que se submeter às profissões que não exigem leitura, não exigem escrever e muito menos interpretar. Assim também não saberá, ou terá mais dificuldade de conhecer, pois terá dependência da comunicação oral, muitas vezes manipulada, para conhecer as leis que garantem seus direitos. Ficará à mercê das semioses da imagem, da comunicação verbal, ou da versão oral das pessoas próximas, sem ter oportunidade de conhecer fatos ou oportunidades na origem, ficando sem as condições de produzir e registrar uma leitura de mundo mais complexa ou com pesquisas em documentos escritos.

Ao ser obrigado a dedicar uma grande parcela de tempo para as avaliações escolares e de larga escala, professores, inconscientemente, perdem a oportunidade e um precioso tempo para pesquisar métodos de como ensinar e aprender a língua materna para formar pessoas com autonomia, com poder de transformação social, e terão que organizar as avaliações nos limites de complexidade da escrita que foi possível ensinar.

Esses são efeitos que as instituições escolares, indiretamente, impõem aos professores e professoras, que são responsáveis diretos por avaliar o desempenho das crianças que as frequentam conforme o calendário ou organização de ensino e aprendizagem do conteúdo curricular que lhes são entregues.

Diante dessas interferências e do controle das instituições que dão provimento às instituições escolares locais, surge a inquietação que os professores e professoras também poderiam considerar: como, por quem e com que finalidade devem ser organizadas as ações e práticas pedagógicas de ensino e de avalição escolar? Seria interessante conhecer um pouco mais sobre os órgãos controladores das instituições escolares.

\section{QUEM MANDA: A AVALIAÇÃO ESCOLAR OU OS EXAMES DE LARGA ESCALA?}

Afinal, os exames de larga escala devem conduzir os processos de formação e de ensino e aprendizagem do conteúdo escolar? Ou seriam os professores e professoras que deveriam conduzir estes processos na educação, com alto grau de consciência linguística, complexidade e motivação adequados às condições de ensino e aprendizagem nas escolas em que atuam e das necessidades de estudantes, dos conteúdos escolares necessários para a formação crítica, voltada para o protagonismo social, econômico e político de alunos e alunas? Ou ainda, será que os processos de formação do indivíduo e de ensino e aprendizagem dos conteúdos ensinados nas escolas que deveriam regular a complexidade nos exames de larga escala? Talvez possa ser impossível dar conta desta questão diante da contemporaneidade em que vivemos. Mas vou permear as periferias da questão.

Se as ações pedagógicas de alfabetização, de ensino da escrita da língua materna, da língua portuguesa, deveriam se centrar, segundo Dangió \& Martins (2018) no alto grau de consciência, na complexidade e na motivação, a ausência ou na sua não consideração nos processos de ensino e aprendizagem da escrita da língua materna, implica na formação de pessoas com dificuldades para desenvolver uma visão de mundo com a identificação das forças discursivas que atuam e controlam a sociedade. A situação se torna mais difícil quando há intencionalidade em ignorar as três exigências, por parte de quem organiza os exames de larga escala, para atender interesses específicos das instituições que os organizam. A pressão por resultados, por verbas, quase que "obriga" e condiciona a professores e professoras da alfabetização e letramentos iniciais aos cursos universitários, de ensino e aprendizagem da escrita na língua portuguesa, a ensinar para que estudantes tenham condições de responder os exames, não para que estes aprendam a ler, escrever e interpretar com alto grau de consciência, com complexidade e motivação de ampliar uma visão de mundo transformadora, por exemplo. 
Os exames de larga escala são encomendados e aplicados pelas instituições controladoras, como o Instituto Nacional de Estudos e Pesquisas Educacionais Anísio Teixeira, INEP², que para facilitar o controle sobre o tipo de conteúdo das avaliações ministradas pelos professores e professoras, organiza o $\mathrm{BNI}^{3}$ (Banco Nacional de Itens) (link no rodapé). Este controle, que aparentemente facilita a vida de professores e professoras, pois não precisam mais pensar, elaborar e formular também as questões das provas de avaliação escolar, o BNI as fornece, inclusive com a resposta correta, também incita a fiscalização, por extensão e por imposição discursiva da sociedade, através de formação de opinião através da imprensa dominante e patrocinada pelos órgãos controladores dos exames de larga escala, e que também doutrina os próprios estudantes e seus responsáveis, que farão de tudo para exigir aulas voltadas para a aprovação nos exames de larga escala.

Mas além do controle local, os principais controles, estes, na maioria dos casos, extremamente autoritários, são os exercidos pelas empresas e instituições mantenedoras das escolas como as secretarias municipais e estaduais de educação, empresas privadas de educação, empresas de auditoria educativa, escolas confessionais, escolas formadas por

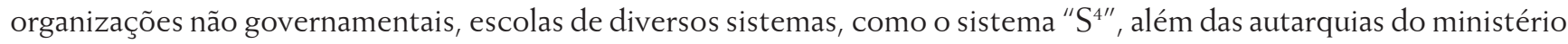
da educação, empresas ou órgãos externos à escola, e ainda por entidades ou instituições internacionais vinculadas a grandes empresas globais como a $\operatorname{OECD}^{5}$ (The Organisation for Economic Co-operation and Development), à $\mathrm{ONU}^{6}$ (Organização das Nações Unidas), UNESCO ${ }^{7}$ (Organização das Nações Unidas para a Educação, a Ciência e a Cultura), ou nacionais como o próprio INEP, autarquia ligada diretamente ao MEC $^{8}$ (Ministério da Educação e Cultura). O INEP9 (link no rodapé), disponibiliza página com a relação de exames educacionais nacionais e internacionais de larga escala, como "Avaliação in loco", Celpe-Bras, Enade, Encceja, Enem, Revalida, Saeb, ArcuSul, Erce, Pirls, Pisa, Riaces, que aplica e controla.

Em seu documento/projeto anual justificando recursos para a análise de dados do SAEB (Sistema de Avaliação da Educação Básica) Edição 2017 Projeto Básico ${ }^{10}$, mostra exemplos de como os índices são utilizados para distribuição tanto de recursos técnicos como financeiros.

1.16. Os resultados desse índice são utilizados pelo Ministério da Educação para estabelecer metas de desenvolvimento da educação e como critério para a distribuição de recursos técnicos e financeiros, provenientes do Fundo de Manutenção e Desenvolvimento da Educação Básica e de Valorização dos Profissionais da Educação (Fundeb) e outras fontes. Tanto a ANRESC como a ANEB são aplicadas a cada dois anos. (INEP, 2017, p.4) ${ }^{11}$

Estas mudanças e regulamentações afetam as avaliações e os exames para medir o desempenho escolar, para medir se as metas e os objetivos previstos na constituição estão sendo alcançados, como as que tem como base o $\underline{\operatorname{artigo~} 214 \text { da constituição }}^{12}$ que prevê exigências como

I - erradicação do analfabetismo; II - universalização do atendimento escolar; III - melhoria da qualidade de ensino; IV- formação para o Trabalho; V - promoção humanística, científica e tecnológica do país. E incluído pela Emenda Constitucional n ${ }^{\circ} 59$ de 2009 , VI estabelecimento de meta de aplicação de recursos públicos em educação como proporção do produto interno bruto.

O Decreto Lei 9.432 de 29 de junho de 2018 e publicado no diário oficial em 02 de julho de 2018, prevê, conforme o artigo $1^{\circ}$, a regulamentação das políticas nacionais de avaliação e Exames da Educação Básica e compreende, conforme o artigo 4: "I - o Sistema de avaliação da Educação Básica - Saeb; II - o Exame Nacional para Certificação de Competências de Jovens e Adultos - Encceja; e III - o Exame Nacional do Ensino Médio $\underline{\text { ENEM }}^{13 \prime}$. O Saeb é alimentado:

2. INEP - https://www.gov.br/inep/pt-br acessado 16/10/2020

3. BNI - https://www.gov.br/inep/pt-br/areas-de-atuacao/avaliacao-e-exames-educacionais/bni acessado 16/10/2020

4. Sistema S: https://www.politize.com.br/sistema-s-como-funciona/ e https://www12.senado.leg.br/noticias/glossario-legislativo/sistema-s Acessado 16/10/2020

5. OECD - http://www.oecd.org/ Acessado 15/05/2019

6. ONU - https://brasil.un.org/pt-br/sdgs Acessado em 15/05/2019

7. UNESCO - https://en.unesco.org/ Acessado 15/05/2019

8. MEC - https://www.mec.gov.br/ Acessado 15/05/2019

9. INEP - Relação de exames: https://www.gov.br/inep/pt-br/areas-de-atuacao/avaliacao-e-exames-educacionais Acessado 16/10/2020.

10.INEP - http://download.inep.gov.br/educacao_basica/saeb/2017/documentos/projeto_basico_SAEB_2017_V6.pdf e https://www.gov.br/ inep/pt-br/areas-de-atuacao/avaliacao-e-exames-educacionais acessado 18/10/2020

11.INEP - repete link de 10.

12.Art 214 da Constituição Federal: http://www.planalto.gov.br/ccivil 03/Constituicao/Constituicao.htm\#art214. Acessado 23/07/2018.

13.ENEM: https://enem.inep.gov.br Acessado em 23/07/2018 
a) com os resultados da provinha Brasi ${ }^{14}$;

b) com os resultados da Avaliação Nacional da Alfabetização ${ }^{15}$ (ANA);

c) com os resultados da Avaliação Nacional do Rendimento Escolar, ou a popular Prova Brasil ou ainda Anresc ${ }^{16}$;

d) com os resultados do ENCCEJA ${ }^{17}$ (Exame Nacional para Certificação de Competências de Jovens e Adultos);

e) com resultados do ENEM $^{18}$ que além de possibilitar acesso a cursos de grande número de Universidades Federais, cursos técnicos e superiores de Institutos Federais, $\underline{\text { SISU }}^{19}$ e $\underline{\text { SISTEC }}^{20}$ cursos em Universidades privadas, e universidades de países como Portugal, o desempenho no exame classifica os candidatos a financiamento estudantil, como o $\underline{\mathrm{FIES}}^{21}$, e bolsas de estudo como o $\underline{\mathrm{PROUNI}}^{22}$, por exemplo. No entanto o ENEM "tem como finalidade principal a avaliação do desempenho escolar e acadêmico ao fim do Ensino Médio." Além disso, existe uma versão do ENEM para pessoas privadas de liberdade. "O Enem PPL ${ }^{23}$, ou para pessoas privadas de liberdade e jovens sob medida socioeducativa que inclua privação de liberdade, tem como finalidade principal a Avaliação do Desempenho Escolar e Acadêmico ao fim do Ensino Médio."

f) com os resultados do SAEB, que compõem o IDEB, mas são os índices do IDEB que servem de subsídio para as políticas de distribuição de recursos e até na formulação de novas estratégias de avaliação.

Criado em 2007 reúne, em um só indicador, os resultados de dois conceitos igualmente importantes para a qualidade da educação: o fluxo escolar e as médias de desempenho nas avaliações. [...] Ele é calculado a partir dos dados sobre aprovação escolar, obtidos no Censo Escolar, e das médias de desempenho nas avaliações do Inep, o Sistema de Avaliação da Educação Básica (Saeb) - para as unidades da federação e para o país, e a Prova Brasil - para os municípios. [...] O Ideb agrega ao enfoque pedagógico dos resultados das avaliações em larga escala do Inep a possibilidade de resultados sintéticos, ... É a ferramenta para acompanhamento das metas de qualidade do Plano de Desenvolvimento da Educação (PDE) para a educação básica, que tem estabelecido, como meta, que em 2022 o Ideb do Brasil seja 6,0-média que corresponde a um sistema educacional de qualidade comparável a dos países desenvolvidos. $\left(\underline{\mathrm{IDEB}}^{24}\right)$

g) e por último, como uma forma de pressão no sentido inverso, já que existe uma "meta para que até 2022 o Ideb do Brasil seja 6,0", existem as avaliações internacionais e entre elas destacamos os Estudos Regionais Comparativos, ERCE/LLGE ${ }^{25}$, para avaliar a qualidade da educação no ensino fundamental dos países da América Latina e Caribe; o Setor Educacional Mercosul $\left(\underline{\mathrm{SEM}}^{26}\right)$, a Pesquisa Internacional sobre Ensino e Aprendizagem "Teaching and Learning International Survey Talis ${ }^{27 \prime \prime}$ que coleta dados de educação básica em mais 34 países com informações referentes a escolas e professores e é financiada pela $\underline{\mathrm{OECD}}^{28}$ (Organisation for Economic Co-operation and Developmente). Outro programa patrocinado pela OECD é o PISA $^{29}$ (Programme for International Student Assesment) ou Programa Internacional de Avaliação de Estudantes ${ }^{30}$. A metodologia visível empregada pelo INEP é a comparação dos índices obtidos por estudantes brasileiros com os índices por outros países, dentro do mesmo exame de larga escala, ou ainda entre exames diferentes, produzindo assim os efeitos ideológicos pretendidos por instituições, entidades, governos e empresas interessadas.

14.Provinha Brasil: http://portal.inep.gov.br/web/guest/provinha-brasil Acessado 23/07/2018

15.ANA - http://portal.mec.gov.br/component/tags/tag/36188 Acessado 23/07/2018.

16.ANRESC - http://portal.mec.gov.br/busca-geral/211-noticias/218175739/2888-sp-209483810 Acessado 01/03/2021

17.ENCCEJA - http://encceja.inep.gov.br/encceja/\#!/inicial Acessado 27/07/2018

18.ENEM - https://enem.inep.gov.br Acessado 27/07/2018

19.SISU - http://www.sisu.mec.gov.br/ Acessado 27/07/2018

20.SISTEC - http://sistec.mec.gov.br Acessado 27/07/2018

21.FIES - http://fies.mec.gov.br/

22.PROUNI - http://siteprouni.mec.gov.br/

23.ENEM PPL - http://portal.inep.gov.br/enem-ppl Acessado 01/03/2021

24.IDEB - http://inep.gov.br/web/guest/ideb Acessado 27/07/2018

25.ERCE-ILECE - http://inep80anos.inep.gov.br/inep80anos/presente/erce-llece/132 Acessado 27/07/2018

26.SEM - http://inep.gov.br/web/guest/mercosul-educacional Acessado 23/07/2018

27.TALIS - http://inep.gov.br/web/guest/pesquisa-talis link acessado em 23 de Julho de 2018.

28. OECD - http://www.oecd.org/

29.PISA - http://www.oecd.org/pisa/

30.PISA - http://inep.gov.br/web/guest/pisa 
As avaliações acima descritas, são promovidas e gerenciadas pelo $\underline{\mathrm{INEP}}^{31}$, uma autarquia do MEC, criada em 1937, que sobrevive a diversos regimes de governo, atuou com diferentes papéis sempre ligados à educação, e hoje é responsável pelas avaliações de larga escala do ministério da Educação e Cultura, inclusive coordenando as avaliações internas, a compilação, organização e adequação dos dados obtidos e dos resultados.

Após a geração dos índices educacionais, as inúmeras provas e avaliações nas escolas e as avaliações e exames de larga escala cabe continuar questionando: por que os resultados das avaliações do dia-a-dia da escola são diferentes dos resultados das avaliações em larga escala em leitura, gramática e produção de texto e interpretação? Ou será que são iguais? O caminho comum, especialmente através da imprensa devidamente aliciada, é culpar o professor e ou culpar o aluno pelo resultado.

Poucos veículos da grande imprensa, escrita, falada, digital e televisiva, formadores da opinião pública, mostram a realidade da formação dos profissionais que atuam na educação, as reais condições de trabalho destes profissionais nas escolas municipais, estaduais, federais, privadas, confessionais e de outras filiações, o salário da maioria dos profissionais, e também não ressaltam com a devida valoração, as diversidades culturais de estudantes, a diversidade de origem e étnica, a origem linguística que em muitos casos, a língua materna não é a língua portuguesa, as condições sociais e econômicas de cada estudante, e as condições de vida destes estudantes fora do contexto escolar. Evitam assim que a sociedade se organize para exigir do Estado e das empresas e instituições mantenedoras, as medidas efetivas que criem as condições para que os profissionais da educação e estudantes possam desenvolver processos educativos para formar pessoas com potencial para, segundo Dangió \& Martins (2018), obter um alto grau de consciência, complexidade e motivação para o ensino, aprendizagem e pesquisa.

Após conhecer um pouco mais sobre os mecanismos de atuação e financiamento das autarquias e organizações que controlam as avaliações e os exames de larga escala, acima descritas, seria ingenuidade ou seria pertinente continuar questionando e fazendo uma análise crítica da relação entre as avaliações escolares e os exames de larga escala: seriam estas instituições as responsáveis em promover os efeitos discursivos e ideológicos para produzir processos educacionais ineficazes para a formação de pessoas sem consciência crítica, avessas a complexidade e sem motivação?

Portanto, reafirmo aqui, que este debate deveria considerar as condições reais de vida de estudantes e dos profissionais da educação, particularmente de professores e professoras, para ampliar e ou criar conhecimentos sobre, não só da relação entre a avaliação escolar com os exames de larga escala, mas sobretudo do papel das avaliações e exames na humanização dos próprios processos de avaliação.

\section{HUMANIZAR AS ATIVIDADES HUMANAS?}

A continuidade da discussão sobre o desafio de como fazer das aulas de língua portuguesa, especialmente das avaliações escolares da disciplina, tanto das avaliações escolares, curriculares, como as de larga escala, processos de humanização, pode estar na necessidade em conhecer mais de como nós entendemos de quem somos, para nós mesmos e para a coletividade. A discussão sobre a descrição que fazemos de nós mesmos está dividida entre "trabalho e linguagem". De acordo com Ghiraldelli Jr (2014, p.63) "A linguagem é, portanto, o elemento para o qual olhamos, de modo a podermos pensar em um retrato mais condizente de nós na atualidade, segundo um paradigma que não é mais o do trabalho."

Com a quebra do paradigma a favor da linguagem, talvez possa ser possível encontrar propostas pedagógicas para os problemas de ensino e aprendizagem da língua portuguesa, que a princípio, insiste e resiste em atender a parte mecânica do ensino da língua, o ensino do código. Segundo Antunes (2007, p. 54) "..., o uso da língua, além da gramática, comporta um léxico (em línguas como a nossa, com cerca de 500 mil palavras) e supõe ainda regras de textualização e regras de interação, decorrentes das situações sociais em que ocorre a atividade verbal." A humanização das atividades de ensino e aprendizagem da língua materna, concebe a língua como um processo de interação e cultural, a língua como um produto histórico e cultural das atividades humanas, não como uma faculdade natural das pessoas. É o uso social da língua, que compreende aprender principalmente os gêneros enunciativos e textuais que são necessários para as práticas sociais nas diferentes esferas das atividades humanas.

31.INEP - http://inep.gov.br/historia 
Formar pessoas para a humanização das atividades avaliativas nas escolas requer a apropriação de conceitos que deixem menos utópica esta perspectiva. O conceito sobre nós mesmos, de que não somos trabalho, de que somos linguagem, e de que os processos de ensino e aprendizagem, desde o início da vida escolar, desde a alfabetização e ou do letramento, ou ainda de quando iniciamos a ouvir e entender as palavras das mães, os processos comunicacionais no ensino de língua portuguesa precisam ter um olhar para a língua como prática social, humanizando os processos de avaliação da aprendizagem da língua nas escolas.

A pedagogia já foi influenciada por esse movimento de redescrição de nós mesmos. Também ela notou que estamos trocando de paradigma. Ela já tem sido instigada por estudos que privilegiam a linguagem. Ela própria, inclusive, tem-se voltado para métodos de alfabetização que, enfim, são parte da atividade dos que geraram linguagem e a sofisticaram, alguns filósofos da educação e pedagogos já sentiram que cada vez mais o ensino deve observar melhor os processos comunicacionais. (Ghiraldelli Jr., 2014, p.63/64)

A importância da alfabetização, vista também como processo de letramento linguístico, inicialmente voltado para a aprendizagem da escrita da língua materna, sua contribuição para a humanização também pode estar na identificação dos modismos ou mudanças que surgem e são divulgadas como "salvadoras", e que muitas vezes são apenas o retorno de teorias anteriormente aplicadas e que não deram certo, ou que são apenas uma nova forma de controlar e impedir que as crianças possam adentrar aos novos modos de cultura e conhecimento por meio da leitura e da escrita. Segundo Mortatti (2006, p.15)

[...] em defesa de seu direito de, por meio da conquista do sentido da leitura e escrita, serem resgatadas do abandono da escuridão e da solidão e não capitularem frente à proibição de ingressarem no novo mundo prometido.

Ao nos representarmos como linguagem ainda sim estamos sujeitos a nos mantermos a serviço, ou submetidos, até de forma inconsciente, achando que estamos lutando pela liberdade ou por um mundo melhor, servindo à propósitos de quem quer manter ou ampliar a dominação, a padronização, a homogeneidade social e tratar estudantes como massa amorfa. "Pessoas que se enquadram cegamente no coletivo fazem de si mesmas meros objetos materiais, anulando-se como sujeitos dotados de motivação própria" (ADORNO, 1995, p. 01).

Profissionais da educação sofrem muito, mesmo professores e professoras que promovem o combate a dominação, que superam os seus próprios limites, mas a serviço da desumanização da educação, pois as próprias dificuldades nas condições de trabalho, fazem da profissão de professor uma profissão contraditória. Limites, que internalizaram nos cursos de formação e licenciatura, impostos peremptoriamente pelo sistema educacional, tanto público como privado, que tem como objetivo claro a manutenção do sistema econômico, político e social em vigor e que privilegia a autoalienação inconsciente.

Embora a transformação social não dependa exclusivamente e ou individualmente das ações do professor e da professora, a educação transformadora e libertadora a partir do professor e da professora e das avaliações escolares, só será possível após professores ou professoras perceberem em si os condicionamentos a que foram ou são submetidos e que propagam sem ter consciência. Assim, poderão, ou não, mas conscientemente, oferecer a seus estudantes processos de ensino e aprendizagem, seguidos de avaliações motivadoras, desalienantes e desreificadoras. A esperança maior ainda são, quase que unicamente, professores e professoras.

Um exemplo de como estudantes brasileiros estavam condicionados, alienados ou reificados pela falta de oportunidades para estudar está no fato de que, no início, em 2005 e nos anos seguintes, sobrarem recursos, na oferta das bolsas do PROUNI.

Costa (2017, p. 157) compilou uma tabela com o número e porcentagem de bolsas ociosas, entre 2005, início do programa, e 2010. 
Tabela 3 - Percentual de bolsas ociosas do PROUNI (BRASIL, 2005-2010)

\begin{tabular}{cccc}
\hline Ano & Bolsas ofertadas & Bolsas ocupadas & Vagas ociosas \\
\hline 2005 & 112.275 & 95.565 & $14,88 \%$ \\
2006 & 138.668 & 109.009 & $21,38 \%$ \\
2007 & 163.854 & 105.546 & $35,57 \%$ \\
2008 & 225.005 & 124.607 & $44,60 \%$ \\
2009 & 247.643 & 161.354 & $34,84 \%$ \\
2010 & 240.441 & 152.697 & $36,49 \%$ \\
$2005 / 2010 \Delta(\%)$ & $114,15 \%$ & $59,78 \%$ & - \\
\hline
\end{tabular}

Fonte: Relatório do TCU/MEC/SISPROUNI

Fonte: Costa e Ferreira ( 2017, p.157)

Também é papel e parte da missão de um professor ou professora motivar, incentivar ou oferecer condições e oportunidades para que estudantes olhem para o mundo, sintam a "catarse", não só nos conhecimentos que estudam, mas também compartilhando informações sobre o acesso à oportunidades para bolsas de estudo, para financiamento estudantil, para perspectivas de empreendedorismo, de trabalho, de renda, de redistribuição de renda, com dignidade, e não, segundo Sabino e Abilio (2019) a "Uberização - o Empreendedorismo como novo nome para a exploração" ${ }^{\text {"32, }}$ como foi imposto pelo plano econômico do governo brasileiro que assumiu em 2019.

No entanto não se pode ignorar de que os sistemas políticos e econômicos dominantes no Brasil e no ocidente estão em crise profunda. E para significar o estado de crise para as pessoas, oportunidades não são divulgadas. $\mathrm{Na}$ própria escola existe a resistência em fazer esta divulgação para estudantes. O reflexo visível dessa crise é sempre a falta de recursos e a falta de oportunidades.

Infelizmente, a tendência é transformar o professor e a professora, especialmente o professor e a professora das escolas de educação básica e ensino médio, e por incrível que possa parecer, também os professores e professoras de inúmeras universidades, de intelectuais, pensadores e educadores para meros repassadores de um conhecimento colonizador, de submissão, pois apenas o multiplicam e reproduzem a serviço de academias colonizadoras e de dominadores. Esta situação está sendo acentuada com a pandemia da Covid-19, onde prevalece o ensino remoto, em todos os níveis e esferas escolares e educacionais, afastando os profissionais da educação presencial de estudantes.

Outro problema é a falácia da possibilidade de substituir profissionais da educação pelas tecnologias de comunicação digital como internet, computadores e telefones celulares, que deveriam colaborar com a relação entre estes profissionais e estudantes.

Estes problemas, anteriormente relatados, não são só brasileiros, mas podem ser analisados em termos mundiais através das entrevistas publicadas por Honorato e Neri (2020) em "História da Educação e Covid-19: crise da escola segundo pesquisadores africanos (Akanbi, Chisholm), americanos (Boto, Civera, Cunha, Kinne, Rocha, Romano, Rousmaniere, Southwell, Souza, Taborda, Veiga, Vidal) e europeus (Depaepe, Escolano, Magalhães, Nóvoa) ${ }^{\prime \prime 33}$ com entrevistas com educadores de diferentes países.

Portanto, para nossa reflexão, para que profissionais da educação possam humanizar a educação e os processos de avaliação, tanto escolares como de larga escala, significa nos conhecer a nós mesmos, nos identificar como linguagem e não como trabalho, perceber quem somos e o que sabemos. Ao percebermos os discursos que enfrentamos também identificamos quais podemos valorizar ou não, ao lançar um olhar para o mundo, ao rejeitar programas e governos que pretendem criar retrocessos nos direitos trabalhistas com um falso empreendedorismo, ao perceber a educação pelo mundo a fora e os problemas enfrentados por outros educadores, em tempos de pandemia, e também no uso das tecnologias digitais de comunicação fortalecemos nosso poder e conhecimentos para desenvolver ações pedagógicas humanizadoras nos processos de ensino e aprendizagem de longo prazo, que ampliam a consciência

32. Uberização: https://doi.org/10.33239/rtdh.v2i2.53 Acessados em 01/03/2021.

33. História da Educação e Covid-19: http://periodicos.uem.br/ojs/index.php/ActaSciEduc/article/view/54998/751375150637 e https:// doi.org/10.4025/actascieduc.v42i1.54998 acessado em 17/10/2020. 
linguística, a complexidade dos processos de ensino e aprendizagem da escrita de línguas e a motivação para o ensino e aprendizagem, não com a finalidade de apenas classificar a educação brasileira em relação aos demais países membros e participantes das organizações avaliadoras, ou para distribuir recursos, mas para transformar a relação com o sistema capitalista selvagem.

\section{CAPITALISMO HUMANIZADO, É POSSÍVEL?}

Humanizar a educação, humanizar as avaliações escolares e os exames de larga escala significa formar seres humanos que olham para outros seres humanos como seus semelhantes e com o propósito de oferecer bem-estar e dignidade à sociedade, confrontando a proposta capitalista e neoliberal de trabalho, lucro, submissão a qualquer preço.

Nos perceber como linguagem, é um passo relevante para tornar possível a formação de seres humanos humanizados, ultrapassa os limites das avaliações escolares e de larga escala segmentadas por conteúdos como língua portuguesa, matemática e ciências. Na realidade, a humanização das avaliações escolares e dos exames de larga escala, estaria em intervir com a linguagem nas práticas sociais de avaliação.

A linguística crítica é herdeira de todas essas tendências na história da filosofia dos séculos passados. Ela nasceu a partir da conscientização de que trabalhar com a linguagem é necessariamente intervir na realidade social da qual ela faz parte. Linguagem é, em outras palavras, uma prática social. A linguística também o é. (RAJAGOPALAN, 2016, p. 126/127)

Essa intervenção, que também implica em reorganizar conteúdos curriculares escolares, a Base Nacional Comum Curricular, $\mathrm{BNCC}^{34}$, que já é organizada prevendo as exigências dos exames de larga escala como o vestibular e a prova do ENEM, e que apresentam um viés ideológico voltado para atender as exigências do mercado de trabalho.

A radical superação da sociedade capitalista precisa ocorrer com um movimento coletivo guiado por um projeto conscientemente assumido de construção de uma sociedade na qual a produção e a reprodução da riqueza material e espiritual estejam direcionadas para a elevação qualitativa das necessidades de todos os seres humanos. (Duarte, 2016, p. 14)

Para fazer frente ao desafio de superar os instrumentos e as limitações capitalistas, dentro do próprio sistema capitalista, ao alcance de professores e professoras, é fundamental conhecer, entender a sociedade do entorno da escola, a que tipo de escola estamos vinculados e quais os propósitos desta, para quê e por quem ela foi criada. No PPP da escola deveria estar descrito a motivação de existência da escola. Segundo Saviani e Duarte (2015, p.180) “O horizonte que deve nortear a organização do ensino médio é o de propiciar aos alunos o domínio dos fundamentos das técnicas diversificadas utilizadas na produção, e não o mero adestramento em técnicas produtivas". Mais adiante na mesma página, os autores apresentam a "escola ativa" como a alternativa para uma escola com a "visão estreitamente profissionalizante e pragmática que pretende ligar o ensino diretamente às demandas do mercado."

Com estas informações, caberia, num segundo momento, aos professores e professoras, atuar de forma incisiva junto aos pais e aos próprios colegas professores e professoras, com o intuito de incluir no $\mathrm{PPP}^{35}$ da escola em que atuam, a proposta de formar pessoas com autonomia, com consciência crítica, humana, política, social e linguística, com complexidade e motivações que possam potencializar a circulação das pessoas nas diferentes esferas das atividades humanas.

Um modelo com fundamentação é a proposta para construir um Plano Político Pedagógico Dialógico do Instituto Paulo Freire ${ }^{36}$. Enquanto isso, como adendo à $\mathrm{BNCC}$, o MEC apresenta apenas um exemplo de PPP ${ }^{37}$.

Com o apoio dos pais dos alunos, da sociedade do entorno da escola, abre-se a oportunidade para uma escola criativa. Segundo Saviani e Duarte, (2015, p.180/181) citando o pensamento de Gramsci (1975, pp.486-487; na edição brasileira, 1968, pp.123-125) "E, para ele, o coroamento dessa escola ativa era a escola criativa, entendida como o momento em que os educandos atingiam a autonomia." A professores e professoras seria possível saber

34.BNCC - Disponível em http://basenacionalcomum.mec.gov.br/images/BNCC_EI_EF_110518_versaofinal_site.pdf Acesso em 25 de Jan de 2020.

35.Projeto Político e Pedagógico: Disponível em http://www.scielo.br/pdf/ccedes/v23n61/a03v2361.pdf acesso em 25 de Jan. de 2020.

36. Proposta para um Plano Político Pedagógico Dialógico: Disponível em http://www.ia.ufrrj.br/ppgea/conteudo/conteudo-2007-2/T1-3SF/ Planejamento_Pol\%EDtico_Pedag\%F3gico.pdf acesso em 25 de Jan. de 2020.

37.Projeto Pedagógico do $\bar{M} E C$ : Disponível em http://basenacionalcomum.mec.gov.br/images/implementacao/dia_discussao_projeto_ pedagogico_v_prof.pdf acesso em 25 de Jan. de 2020. 
de antemão, por conta do PPP da escola, por causa do contexto político, social, geográfico e econômico em que a escola está inserida, se é possível inferir ou não, de que os exames de larga escala foram elaborados para atender aos interesses e demandas de mercado mais amplo ou global, e, se conhecedores da contradição, segundo Saviani e Duarte $(2015$, p. 2$)$

entre a especificidade do trabalho educativo na escola - que consiste na socialização do conhecimento em suas formas mais desenvolvidas - e o fato de que o conhecimento é parte constitutiva dos meios de produção que, nesta sociedade, são propriedades do capital e, portanto, não podem ser socializados.

Cientes destas contradições, seria possível organizar forças para movimentos a fim de atender aos "interesses das classes dominantes", (SAVIANI e DUARTE, 2015, p.2), ou não, sempre como profissionais conscientes do que estamos fazendo, ou "forças para movimentos favoráveis aos interesses da classe trabalhadora". (SAVIANI e DUARTE, 2015, p.3). Nas duas situações, a escola poderia oferecer aos seus alunos uma visão de escola criativa voltada para a autonomia, que traria possibilidades de superação de inúmeras situações conflituosas e problemáticas existentes na comunidade onde o estudante vive e convive socialmente.

$\mathrm{Na}$ conjuntura atual, segunda década do século XXI e na América Latina, o tensionamento entre as forças capitalistas e socialistas dificulta a conciliação já que predomina a escola que pretende formar trabalhadores alienados, que servem à causa capitalista, para manter a conjuntura de submissão e servidão a salários irrisórios, enquanto que uma escola criativa voltada para a autonomia potencializaria a formação de pessoas engajadas na luta por seus direitos, por dignidade humana e oportunidades de trabalho e estudo de qualidade. Com essa consciência seria possível formar potenciais empreendedores, com visão e recursos para fazer frente às armadilhas capitalistas impostas às pessoas.

Retomando nosso tema, o sistema capitalista alimenta quem organiza os exames de larga escala. O embate que denuncia a diferença nos resultados dos estudantes nas avaliações escolares de língua portuguesa e o resultado nos exames de larga escala, a responsabilidade do fracasso nos exames de larga escala, como o ENEM e o PISA, que é atribuído aos professores e professoras e alunos e alunas. E os discursos, nesse sentido, são amplamente divulgados por grande parte da imprensa, nos meios de comunicação, internet e redes sociais. Mas se fosse possível atribuir uma responsabilidade ao professor e à professora pelo baixo desempenho dos alunos nos exames de larga escala seria a de que se dedicam, ao longo de sua jornada de trabalho como educador e educadora, ao estudante para "transmissão da experiência humana acumulada e criatividade que fundem-se na catarse". (DUARTE, 2016, p. 17)

No caso das obras científicas e filosóficas, a catarse ocorre de maneiras não idênticas à catarse estética, o que se explica pelo simples fato de que a arte, ciência e filosofia são tipos distintos de apropriação da realidade pela consciência. Mas as obras desses três campos mais elevados de produção humana podem, pela mediação do trabalho educativo, produzir saltos qualitativos decisivos em termos de desenvolvimento da visão de mundo dos indivíduos. (DUARTE, 2016, P.18)

Enquanto que, os conhecimentos que provocam a catarse nos alunos não são exigidos nos exames de larga escala, estes, os exames de larga escala, tentam exigir que o aluno mostre que aprendeu a reproduzir um conhecimento padrão, homogeneizado, condizente com o que Saviani e Duarte (2015, p. 180), citando Gramsci (1975, p. 486-487; na edição brasileira, 1968, p. 123-125), propugnava como "de uma escola do tipo "desinteressado"".

Portanto, formar pessoas humanas humanizadas e humanizadoras é incluir nas práticas pedagógicas e de avaliação propostas de ensino e aprendizagem que possam atender à formação de pessoas com o desenvolvimento do seu potencial de transformação e superação da realidade e visão consciente do mundo em que vivem.

Língua e gramática podem ser uma solução se soubermos ir adiante, muito além da gramática, muito além até mesmo da língua, para alcançar a nós mesmos e aos vestígios mais sutis da cultura, da história, dos discursos todos que teceram e tecem os versos de cada um. (ANTUNES 2014, p.161)

Priorizar a formação da pessoa humana também implica em buscar com que esta pessoa se torne crítica e possa, por exemplo, fazer a distinção entre as armadilhas discursivas, ou lutar pela manutenção de um tipo de sociedade, em detrimento, de uma sociedade que desenvolva condições de superação. Entre os exemplos que apresentam o caráter de manutenção da sociedade capitalista estão a "pedagogia das competências" de Philipe Perrenoud e as ilusões ideológicas representadas pela sociedade do conhecimento.

Quando educadores e psicólogos apresentam o "aprender a aprender" como síntese de uma educação destinada a formar indivíduos criativos, é importante atentar para um detalhe fundamental: essa criatividade não deve ser confundida com busca de transformações radicais na realidade social, busca de superação radical da sociedade capitalista, mas sim criatividade em termos de capacidade de 
encontrar novas formas de ação que permitam melhor adaptação aos ditames da sociedade capitalista. [...] A assim chamada sociedade do conhecimento é uma ideologia produzida pelo capitalismo, é um fenômeno no campo da reprodução ideológica do capitalismo. (DUARTE,2008, p.12-15)

Antes de ir para as considerações finais, gostaria de destacar uma ideia que liberta as pessoas, a presunção de lutar por um lugar em que o acesso às ideologias e ideias da escola possa acontecer para todos e em todos os lugares. A luta do MST (Movimento dos Trabalhadores Rurais Sem Terra) por uma proposta de escola em que, segundo Mariano (2011, p. 192),

cabe ao estado a responsabilidade pela manutenção da escola pública na sua totalidade (acesso, permanência, qualidade), mas cabe à comunidade a sua gestão. Isso quer dizer que a escola deve ser um aparelho público e não um aparelho de Estado.

Nessas condições, existem outros desafios como manter o acesso, ou universalizar o acesso aos benefícios que hoje estão vinculados aos resultados obtidos nos exames de larga escala, como os vinculados à Prova do ENEM. Os principais são o SISU, o PROUNI e o FIES, que também são limitadores do sistema capitalista a serem superados.

A vida escolar do estudante, por exemplo, com critérios que possam respeitar e considerar as diversidades geográficas, culturais, econômicas, sociais, etnográficas, sexuais, raciais e religiosas que cada estudante vivenciou e conviveu durante sua vida escolar, seria um método de acesso que não é condicionado ao resultado de apenas uma única avaliação de larga escala, num dado momento, mas que demonstra a história de vida que cada estudante construiu em conjunto com outras pessoas, consciente e motivado para buscar por dignidade em escolas e universidades humanizadoras, mostrando as vivências e superações de sua história de vida estudantil.

\section{CONSIDERAÇÕES FINAIS.}

A humanização e universalização do acesso ao conhecimento, à dignidade, à consciência política, à consciência humana e à educação em todos os níveis, sem, contudo, se submeter a avaliações com exames de larga escala como o ENEM o PISA, oferecendo o histórico escolar, a história de vida, como diagnóstico para ingresso em universidades e para acessar bolsas de estudo ou financiamentos estudantis, sintetiza a proposta central para este artigo.

Com o artigo "O ensino e a aprendizagem da escrita na língua materna: da transdisciplinaridade ao colonialismo implícito nos gêneros exames de larga escala e avaliações do desempenho da aprendizagem dos alunos nas salas de aula" buscou apoio transdisciplinar na Linguística Aplicada (ROJO, 2016), na Linguística Aplicada Crítica (RAJAGOPALAN, 2016), na Análise Crítica do Discurso (BONINI, 2012), nas Pedagogias, da libertação (FEIRE, 1999), interativa (VIGOTSKI, 2017) e Histórico-Crítica (SAVIANI e DUARTE, 2015) para ampliar uma reflexão sobre a relação entre a avaliação escolar aplicada por um professor ou professora de disciplina do currículo escolar, na educação básica e ensino médio, e os exames de larga escala que geram os dados do SAEB e do PISA.

Conhecer, identificar e, quem sabe, desenvolver mais um caminho que possa nos conscientizar, como professores e professoras, sobre os efeitos ideológicos e discursivos que os processos de avaliação escolar e os exames de larga escala provocam a nós e a estudantes, da educação básica ao ensino médio, enquanto participamos dos processos de ensino e aprendizagem da leitura, da interpretação e, em particular, da escrita na língua materna, a língua portuguesa, de colonização e oficial do Brasil monolíngue, motivou-me esta reflexão.

O presente estudo teve também a preocupação de conhecer um pouco mais sobre as instituições nacionais e internacionais que comandam, controlam e aplicam os exames de larga escala, e assim oferecer caminhos que possam identificar a que organizações, governos ou entidades empresariais ou públicas, elas se submetem e pertencem.

Finalizo o presente artigo com a sugestão de ampliar o debate e as ações de intervenção social, entre elas, a de que a transformação nos processos de avaliação escolar e dos exames de larga escala é urgente, substituindo-as e utilizando no seu lugar, como acesso universal aos cursos das universidades, aos financiamentos e bolsas de estudo, a própria história de vida escolar de cada estudante, como um novo histórico escolar, mais complexo e completo, diferente do atual "boletim de notas", no qual seria possível conhecer a história de vida e participação do estudante desde a educação infantil até o Ensino Médio. Uma mudança cultural que pode representar a diferença para uma proposta de ensino da leitura, interpretação e escrita da língua materna com alto grau de consciência, complexidade e motivação. Aos professores e professoras o convite para enriquecer e participar deste debate, como transformadores sociais que somos, com atenção especial para o PPP da escola em que atuamos, presencialmente ou remotamente. 


\section{REFERÊNCIAS}

ADORNO, Theodor W. (1995). Educação e Emancipação. Debate da rádio de Hessen; transmitido em 13 de agosto de 1969 (p. 188). Tradução Wolfgang Leo Maar. São Paulo: Editora Paz e Terra.

ADORNO, Theodor W.(1951). A teoria freudiana e o padrão da propaganda fascista. Disponível em https://nupese.fe.ufg.br/up/208/o/ Theodor_Adorno_-_A_Teoria_freudiana_e_o_modelo_fascista_de_propaganda_1951_.htm? 1349568035 Acesso em 20 Jan. 2020. Reproduzido em Gesammelte Schriften Vol. 8, T. I [Soziologische Schriften] Frankfurt : Surhkamp Verlag, 1975, p. 408-433. Traduzido por Francisco Rüdiger. Publicado originalmente em Psychoanalysis and the Social Sciences $3(408-433) 1951$.

ANTUNES, Irandé (2014). Muito além da Gramática - por um ensino de línguas sem pedras no caminho. Série Estratégias de Ensino $5.1^{\text {a }}$ ed. 6 a reimpressão. São Paulo: Parábola Editorial.

BAKHTIN, Mikhail (1979). Estética da Criação Verbal. Tradução do russo: Paulo Bezerra. $1^{\text {a }}$ ed. 1992. $6^{\text {a }}$ ed. 2011. São Paulo: WMF Martins Fontes, 2011.

BONINI, A. (2012). Ensino de gêneros textuais: A questão das escolhas teórica e metodológicas. Disponível em: https://periodicos.sbu.unicamp. br/ojs/index.php/tla/article/view/8639323 Acessado em 24 de janeiro de 2020. Publicado na revista Trabalhos Em Linguística Aplicada. v.37 (2001). pp. 7-23.

BONINI, Adair (2014). Os gêneros do jornal: o que aponta a literatura da área de comunicação no Brasil?. In: Bonini e outros (Orgs). Os gêneros do jornal. Coleção Linguística volume 4. Florianópolis: Editora Insular. p. 51-70.

COSTA, Danielle Dias da (2017). e FERREIRA, Norma-Iracema de Barros. O PROUNI na educação superior brasileira: indicadores de acesso e permanência. Disponível em http://www.scielo.br/pdf/aval/v22n1/1982-5765-aval-22-01-00141.pdf e DOI: http:// dx.doi.org/10.1590/S1414-40772017000100008 Acesso em 30 de julho de 2018. Artigo publicado na revista Avaliação (Campinas) vol.22 no.1 Sorocaba jan./abr. 2017, pp. 141-163.

DANGIÓ, Meire Cristina dos Santos; e MARTINS, Lígia Márcia. (2018). A alfabetização sob o enfodue bistórico-crítico. Contribuições didáticas. Campinas (SP): Autores Associados.

DARDOT, Pierre, e LAVAL, Christian (2009-2010). A nova razão do mundo - ensaio sobre a sociedade neoliberal. Tradução de Mariana Echalar. Publicação original: Editions La Découverte. Paris: 2009/2010. Boitempo: São Paulo, 2016.

DARDOT, Pierre, e LAVAL, Christian (2014). COMUM - ensaio sobre a revolução no século XXI. Tradução de Mariana Echalar. Publicação original: Editions La Découverte. Paris: 2014. Boitempo: São Paulo, 2017.

D’SOUZA, Radia (2010). As prisões do conhecimento: pesquisa ativista e revolução na era da "globalização". In: Santos, Boaventura Souza e Meneses, Maria Paula. ((Org) 2014 publicado no Brasil). Epistemologia do Sul. São Paulo: Cortez Editora, p. 111-133.

DUARTE, Newton (2008). Sociedade do Conbecimento ou Sociedade das Ilusões? Polêmicas do nosso tempo. $1^{\text {a }}$ Ed. $1^{\text {a }}$ Reimpressão. Campinas, SP: Autores Associados.

DUARTE, Newton (2016). Os conteúdos escolares e a ressureição dos mortos. Contribuição à teoria histórico-crítica do currículo. Campinas, SP: Autores Associados.

FREIRE, Paulo (1999). Pedagogia da Autonomia - Saberes necessários à prática educativa. Coleção leitura. 12 ed. São Paulo: Paz e Terra.

FREIRE, Paulo e MACEDO, Donaldo (2011). Alfabetização: leitura do mundo, leitura da palavra. Tradução: Lólio Lourenço de Oliveira. São Paulo: Editora Paz e Terra Ltda.

GALASTRI, Leandro (2015). Gramsci, Marxismo e Revisionismo. Coleção Educação Contemporânea. Campinas: Autores Associados. GHIRAlDELli JUNIOR, Paulo (2014). O que é Pedagogia. Coleção Primeiros Passos. $4^{\mathrm{a}}$ ed. $13^{\mathrm{a}}$ reimpressão. São Paulo: Brasiliense. 
HOFFMANN, Jussara (2013). Avaliando redações - metodologias e instrumentos de avaliação. $3^{\text {a }}$ ed. Porto Alegre: Editora Mediação.

LINS, Ana Maria Moura (2003). Educação Moderna - Contradições entre o projeto Civilizatório Burguês e as Lições do Capital. Campinas, SP: Autores Associados.

LUCKESI, Cipriano Carlos (2015). Avaliação da aprendizagem - componente do ato pedagógico. $1^{\mathrm{a}}$ ed. $5^{\mathrm{a}}$ impressão. São Paulo: Cortez Editora.

MARIANO, Alessandro Santos (2011). A luta do MST por escolas públicas no campo: possibilidades de fazer uma escola comprometida com a transformação da sociedade. In: História, Educação e Transformação - Tendências e perspectivas para a educação pública no Brasil. Lombardi, José Claudinei e Saviani, Demerval (org.) Coleção memória da Educação. Campinas, SP: Autores Associados. (p. 187-201).

MOITA LOPES, Luiz Paulo da (Org.) (2016). Fotografias da Linguística Aplicada brasileira na modernidade recente: contextos escolares. In: Linguística Aplicada na Modernidade Recente. Festschriff para Antonieta Celani. $1^{\mathrm{a}}$ ed. 2013. $2^{\mathrm{a}}$ reimpressão. São Paulo: Parábola, pp. 15-37.

MORTATTI, Maria Rosário Longo (2006). História dos métodos de alfabetização no Brasil. Conferência proferida durante o Seminário "Alfabetização e letramento em debate", promovido pelo Departamento de Políticas de Educação Infantil e Ensino Fundamental da Secretaria de Educação Básica do Ministério da Educação, realizado em Brasília, em 27/04/2006. Disponível em http://portal.mec.gov.br/seb/arquivos/pdf/Ensfund/alf_mortattihisttextalfbbr.pdf acesso em 24 de Jan. 2020 .

RAJAGOPALAN, Kanavillil (2016). Por uma linguística crítica. Linguagem, Identidade e a questão ética. Língua[gem] 3. $1^{\mathrm{a}}$ ed. 2003, $5^{\mathrm{a}}$ reimpressão, julho de 2016. São Paulo: Parábola.

ROJO, Roxane Elena Rodrigues (2016). Fazer linguística aplicada em perspectiva sócio-histórica - privação sofrida e leveza de pensamento. In: Moita Lopes, Luiza Paulo da (org.). In: Por uma linguística aplicada indisciplinar. São Paulo: Parábola Editorial, $1^{\text {a }}$ ed. $5^{\text {a }}$ reimpressão, pp. 253-276.

SAVIANI, Demerval (2013). História das Ideias Pedagógicas no Brasil. (Coleção memória da Educação). $4^{\mathrm{a}}$ ed. Campinas, SP: Autores Associados.

SAVIANI, Demerval. e DUARTE, Newton (2015). Pedagogia bistórico-crítica e luta de classes na educação escolar. Coleção Polêmicas do nosso tempo. Campinas, SP: Autores Associados.

SOUZA, Joeline Rodrigues de (2012). A formação bumana omnilateral e a proposição da escola unitária de Antonio Gramsci: uma análise à luz da ontologia marxiana. Dissertação de Mestrado no Programa de Pós-graduação em Educação Brasileira - FACED - da Universidade Federal do Ceará. Fortaleza.

VIGOTSKII, L. S. (2017). Aprendizagem e Desenvolvimento Intelectual na Idade Escolar. In: Vigotskii, L. S.; Luria, A. R.; Leontiev, A. N. In: Linguagem, desenvolvimento e aprendizagem. 15 edição. Tradução: Maria da Penha Villalobos. Coleção Educação Crítica. São Paulo: Ícone Editora Ltda. p. 103-117.

Recebido: $25 / 1 / 2020$

Aceito: $12 / 10 / 2020$

Publicado: 4/3/2021 